\title{
Synthesis and Characterization of a Cobalt(III) corrole with an S- bound DMSO ligand
}

Nicolás I. Neuman, ${ }^{* a, b}$ Arijit Singha Hazari, ${ }^{a}$ Julia Beerhues, ${ }^{a}$ Fabio Doctorovich, ${ }^{c}$ Santiago E. Vaillard ${ }^{b}$ and Biprajit Sarkar*[a]

[a] Dr. N. I. Neuman, Dr. A. Singha Hazari, Ms. J. Beerhues, Prof. Dr. B. Sarkar Institut für Anorganische Chemie, Universität Stuttgart, Pfaffenwaldring 55, D70569, Stuttgart, Germany. Email: biprajit.sarkar@iac.uni-stuttgart.de

[b] Dr. N. I. Neuman, Prof. Dr. S.E. Vaillard Instituto de Desarrollo Tecnológico para la Industria Química, INTEC, UNLCONICET Paraje EI Pozo, Santa Fe, Argentina. Email: nneuman@intec.unl.edu.ar

[c] Prof. Dr. F. Doctorovich

Departamento de Química Inorgánica; Analítica y Química Física/INQUIMAECONICET; Facultad de Ciencias Exactas y Naturales; Universidad de Buenos Aires. Ciudad Universitaria; Pabellón II; Buenos Aires (C1428EHA); Argentina

Supporting information for this article is given via a link at the end of the document.

Keywords: Ab initio calculations $\cdot$ Cobalt $•$ Corrole $\cdot$ DMSO $\cdot$ Innocent

\begin{abstract}
We have synthesized a low-spin Co(III) complex of 5,15-bis(4-nitrophenyl)-10-(2methylcarboxyphenyl)corrole with an S-bound dimethylsulfoxide (DMSO) ligand (1DMSO) and determined the coordination mode through X-ray diffraction for the first time. UV-vis-NIR spectral data show that the DMSO ligand does not dissociate in $\mathrm{CH}_{2} \mathrm{Cl}_{2}$ solution, and EPR results indicate that the first oxidation is ligand centered and suggest that not only DMSO remains bound but a second apical ligand, possibly $\mathrm{MeCN}$, binds to the cobalt center. Multiconfigurational wavefunction electronic structure methods (CASSCF/NEVPT2) allowed us to determine that in this complex
\end{abstract}


the corrole behaves as an innocent trianionic ligand and that the $\sigma$-donor effect of the $S$ atom determines the low-spin configuration by raising the energy of the Co $3 \mathrm{dz}^{2}$ orbital. While DFT calculations predict a ground open-shell singlet for both S-bound and O-bound DMSO variants, CASSCF/NEVPT2 calculations predict a closed-shell singlet ground state in both cases. These calculations reproduce considerably well the UV-vis-NIR spectrum of 1DMSO in solution, validating the closed-shell singlet description.

\section{Introduction}

In the last twenty years the coordination chemistry of corroles has become well established, and a great diversity of complexes with various transition metals, as well as non-metals, have been synthesized and characterized. Cobalt has been the most common metal in metallocorrole synthesis since the early work of Kay and Johnson, ${ }^{[1]}$ mainly due to their interest in corrole models for cobalamins (vitamin B12). Cobalt corroles have many catalytic applications in water oxidation, ${ }^{[2]}$ hydrogen evolution, ${ }^{[3]}$ oxygen reduction ${ }^{[4]}$ and carbon dioxide reduction, ${ }^{[5]}$ with all these processes involving chemical changes in apically bound cobalt ligands.

Even neutral $\mathrm{Co}$ (III) corroles display rich apical ligand chemistry, and it has long been known that they can be prepared with two, one or no apical ligands, and that in solution some of these forms may be in equilibrium. The identity and number of apical ligands usually have profound effects on the redox, spectroscopic and magnetic properties of cobalt corroles, in many cases changing the spin state of the complex. ${ }^{[2 \mathrm{~d}, 6]}$

The most common apical ligands in cobalt corroles are triphenylphosphine $\left(\mathrm{PPh}_{3}\right)$ and two pyridine (Py) molecules, and the majority of crystal structures have been reported with these ligands. ${ }^{[7]}$ This is no accident, as $\mathrm{PPh}_{3}$ or $\mathrm{Py}_{2}$ both stabilize a singlet ground state described as [ $\left.\mathrm{Co}(\mathrm{III})\left(\mathrm{Cor}^{3-}\right)\right]$, which is stable in solution over long periods of time, ${ }^{[7 c, 8]}$ although the innocence of $\mathrm{Co}(\mathrm{III})$ corroles with $\mathrm{PPh}_{3}$ apical coordination has been the matter of discussion. ${ }^{[7 \mathrm{~d}]}$ Metallation of corroles with cobalt acetate without a strong apical ligand has also been shown to produce covalently-linked corrole dimers. ${ }^{[8 b]}$ It has also been reported that loss of one apical Py ligand results in openshell singlet species, described as $\mathrm{Co}(\mathrm{II}) \mathrm{Cor}^{\circ-2}$, which are much easier to oxidize. ${ }^{[6]}$ And very recently, ${ }^{[9]}$ it was shown that $\mathrm{Co}(\mathrm{III})(\mathrm{tpfc}), \quad$ (tpfc $=5,10,15$-tris $(2,3,4,5,6$ pentafluorophenyl)corrole, one of the common corroles with highest oxidation potentials) without any Py apical ligands, can be oxidized by $\mathrm{O}_{2}$ to a corrole centered 
radical. The lability of $\mathrm{Co}(\mathrm{III})$ corroles without strong apical ligands to oxidation, together with the tendency towards Py dissociation in certain solvents has meant that crystallization is usually performed adding drops of Py to the crystallization solvent. ${ }^{[2 d,}$ 6]

The search of other simple apical ligands that produce stable Co(III) corrole complexes which can be crystallized is therefore of great interest because it allows larger synthetic flexibility. Particularly, dimethylsulfoxide (DMSO) has been shown to favor pentacoordinated species which leave one apical site free, which then can be used in catalytic processes. ${ }^{[10]}$ So far the coordination mode of DMSO to cobalt(III) corroles has not been established, and it has been assumed in electronic structure calculations $^{[11]}$ that DMSO binds to the cobalt(III) center through the $O$ atom. This assumption resulted in very small calculated singlet-triplet gaps of the order of 0.2 $\mathrm{kcal} / \mathrm{mol}\left(70 \mathrm{~cm}^{-1}\right)$ and a description of the spin state of the complex as an open-shell singlet $(\mathrm{Ar})_{3} \mathrm{Cor}^{\circ 2-} \mathrm{Co}(\mathrm{II})(\mathrm{DMSO})(\mathrm{Ar}=$ aryl) .

In this work we present the synthesis and characterization of a cobalt(III) corrole with one S-bound DMSO ligand, (5,15-bis-(4-nitrophenyl)-10-(2methylcarboxyphenyl)cobalt(III)-DMSO, 1DMSO, Scheme 1), which has been unequivocally proven by X-ray diffraction studies, together with a detailed spectroscopic, electrochemical and computational characterization. Using wavefunction theory (WFT) based electronic structure calculations (complete active space self-consistent field, CASSCF), we show that the S-bound ligation stabilizes a singlet ground state, thus resulting in a stable complex. This work thus for the first time unequivocally establishes the coordination mode of DMSO in cobalt(III) corroles through experimental methods in the solid state. Additionally, it proves the influence of the different binding modes on the electronic structures of the resulting cobalt(III)corrole complexes through state of the art theoretical methods. Furthermore, the multireference wavefunction-based calculations reported here are, to the best of our knowledge, the first ones performed on a complete meso-substituted cobalt corrole. 


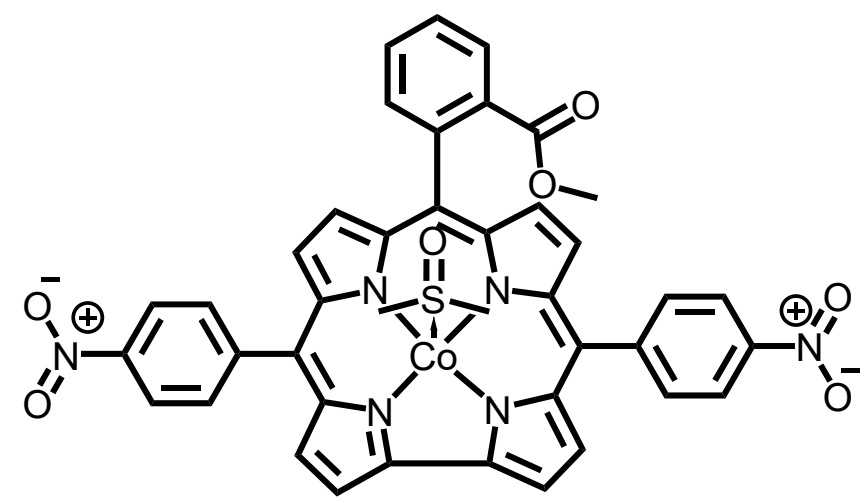

Scheme 1. Molecular formula of 1DMSO.

\section{Results and Discussion}

\section{X-ray Crystallography and structural analysis}

Cobalt(III) corrole 1DMSO was synthesized following the procedure reported by Kadish et al. ${ }^{[10 b,}$ 12] This afforded a bright red powder, which was filtrated, washed several times with $\mathrm{H}_{2} \mathrm{O}$, dried and recrystallized from $\mathrm{CH}_{2} \mathrm{Cl}_{2} / \mathrm{n}$-hexane. Dark red, $\mathrm{X}$ ray quality crystals, were grown from the same solvent mixture, plus a drop of DMSO, by solvent diffusion and slow evaporation (see Figure S1). The molecular structure of 1DMSO is shown in Figure 1 and Figure S2. The cobalt atom sits in a square-pyramidal $\mathrm{N}_{4} \mathrm{~S}$ geometry, $0.235 \AA$ above the $\mathrm{N}_{4}$-plane. The Co-N mean distance is 1.8695(2) $\AA$, and the apical Co-S distance is $2.1331(9) \AA$. These values are compatible with a lowspin $\mathrm{Co}$ (III) center, which is supported by comparison with the Co- $\mathrm{N}$ distances presented by the cobalt corrole with two apical ligands $(\mathbf{2} \mathbf{P y})_{2},{ }^{[2 d]}$ previously reported by us and included in Table 1.

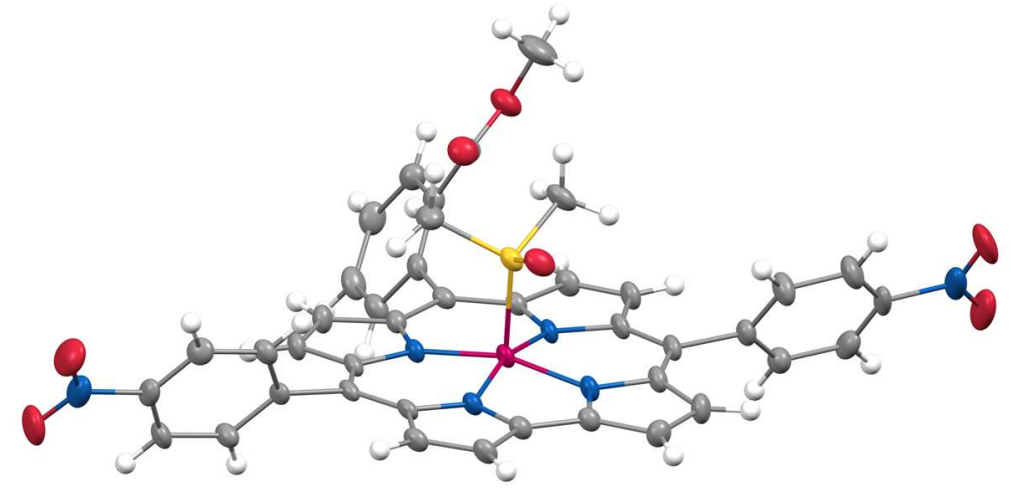

Figure 1. ORTEP representation of 1DMSO. Ellipsoids are drawn at $50 \%$ probability. Grey: C; blue: N; red: O; yellow: S, white: H; fuchsia; Co. 
There are very few examples of S-bound DMSO cobalt complexes (none for cobalt- or any metallo-corroles) in the literature, ${ }^{[13]}$ for which crystal structures have been reported, and few others with O-bound DMSO ligands. ${ }^{[14]}$ Jones et al.[13a] reported a crystal structure (CCDC code: KUQCEG) with two cobalt(III) porphyrins ([Co(III)TMOP(DMSO) $]^{+}$, TMOP = 5,10,15,20-tetrakis(4-methoxyphenyl) porphyrin) with apical DMSO ligands in the unit cell, and $\mathrm{SbF}_{6}{ }^{-}$counterions. The $\mathrm{Co}$ (III) ion in one of these porphyrins is bound to two DMSO ligands through the $S$ atoms (Co-S distances were $2.248 \AA$ and S-O distances were $1.425 \AA$ ), and the porphyrin ring is planar, while the other is bound to two DMSO ligands through the $O$ atoms and is considerably ruffled. These interesting features were noted by the authors but their effect on the electronic structure of the cobalt porphyrins was not discussed. To the best of our knowledge, this is the only example of a structurally characterized Co(III) porphyrin with S-bound DMSO ligands. More recently an S-bound mono-DMSO Co(II)porphyrin was reported by Megiatto et al. (CCDC code: DEZBIW). ${ }^{[13 b]}$ The Co-S distance was 2.441(2) $\AA$ and the S-O distance was 1.487(4) $\AA$. Also, a cobalt(II) pyrazino-porphyrazinato with two O-bound DMSO apical ligands was reported (CCDC code: QOYGER). ${ }^{[14]}$

Table 1. Selected bond distances $(\AA)$ for compound 1 DMSO and 2Py2. ${ }^{6}$

\begin{tabular}{|c|c|c|c|}
\hline & 1DMSO & & $2 \mathrm{Py}_{2}$ \\
\hline Bond & $\begin{array}{c}\text { Distance } \\
\text { (Å) }\end{array}$ & Bond & $\begin{array}{c}\text { Distance } \\
\text { (A) }\end{array}$ \\
\hline Co-N1 & $1.864(2)$ & Co-N1 & $1.897(2)$ \\
\hline Co-N2 & $1.875(2)$ & Co-N2 & $1.905(2)$ \\
\hline Co-N3 & $1.882(2)$ & Co-N3 & $1.871(2)$ \\
\hline Co-N4 & $1.857(2)$ & Co-N4 & $1.875(2)$ \\
\hline Co-s & $2.133(1)$ & Co-N7(Py) & $1.993(2)$ \\
\hline S-O & $1.469(2)$ & Co-N8(Py) & $1.998(1)$ \\
\hline Co- & 0.235 & Co- & 0.004 \\
\hline $\mathbf{N}_{4}$ (plane) & & $\mathrm{N}_{4}($ plane $)$ & \\
\hline Co- & $1.870(1)$ & Co- & $1.887(1)$ \\
\hline$N_{\text {eq }}$ (mean) & & $\mathbf{N}_{\text {eq }}($ mean $)$ & \\
\hline
\end{tabular}

To the best of our knowledge, there are no other cobalt-containing porphyrinoids with DMSO ligands reported in the Cambridge Crystallographic Data Centre. In a report of 
an S-bound sulfoxide Fe(II) porphyrin, ${ }^{[15]}$ the authors discussed that $\mathrm{Fe}(\mathrm{II})$ porphyrins have been observed to be both $\mathrm{O}$ - and S-ligated, as $\mathrm{Fe}(\mathrm{II})$ is considered to be borderline between a hard and soft Lewis acid. ${ }^{[16]}$ Furthermore, they pointed out that the delocalized nature of the porphyrin m-system would tend to soften $\mathrm{Fe}(\mathrm{II})$ and favor S-ligation. Finally, they concluded that the shortening of the Fe-S distance was due to enhanced $\sigma$-bonding, and not to stronger $\pi$-backbonding. The Co-S distance in 1DMSO is considerably shorter compared to the one in the Co(II)porphyrin reported by Megiatto et al., and is shorter than in [Co(III)TMOP(S-DMSO $\left.)_{2}\right]^{+}$, reported by Jones et al., with the caveat that the latter presents an hexacoordinated Co(III) site. The bond length comparisons strongly suggest 1DMSO containing a low-spin Co(III) center with an innocent corrole ${ }^{3-}$ ligand.

\section{Spectroscopic and Electrochemical Characterization}

The IR spectra of solid 1DMSO and free-base $\mathrm{H}_{3} \mathrm{~L} 1$ are shown in Figure S5. The complex shows two peaks at $1012.2 \mathrm{~cm}^{-1}$ and $983.0 \mathrm{~cm}^{-1}$. It has been reported that S-bound DMSO metal complexes show S-O stretching bands in the 1080$1154 \mathrm{~cm}^{-1}$ range, while O-bound DMSO displays S-O stretching in the 862-997 $\mathrm{cm}^{-1}$ range. ${ }^{[17]}$ However, all given examples ${ }^{[17 \mathrm{~b}]}$ of S-bound complexes involved second and third row transition metals. For O-bound DMSO first row complexes frequencies in the $911-957 \mathrm{~cm}^{-1}$ range have been reported. ${ }^{[18]}$ Calculated frequencies for $\mathrm{S}-\mathrm{O}$ stretching in 1DMSO (PBE0/def2$\operatorname{TZVP}(\mathrm{Co}) / \mathrm{CPCM}(\mathrm{MeCN})$ ) were $1069.7 \mathrm{~cm}^{-1}$ for S-O stretching and $984.3 \mathrm{~cm}^{-1}$ for S-O stretching coupled to $\mathrm{CH}_{3}$ rocking. There are also $\mathrm{CH}_{3}$ twisting motions calculated at $1420-1430 \mathrm{~cm}^{-1}$, which could correspond to the experimental peak at $1432.8 \mathrm{~cm}^{-1}$. For the "hypothetical" O-bound complex (1(O-DMSO)), calculated to be $9.6 \mathrm{~kJ} / \mathrm{mol}$ higher in energy than 1DMSO, calculations predict the S-O stretching bands to be at 1021.5 and $942.7 \mathrm{~cm}^{-1}$. Although there is a shift between calculated and experimental frequencies, which is to be expected at this level of theory, calculations show that the O-bound DMSO S-O stretchings are shifted approximately $40-50 \mathrm{~cm}^{-1}$ towards lower frequencies compared to the S-bound case, in agreement with the literature.

The UV-vis spectra of $1 D M S O$ in $\mathrm{CH}_{2} \mathrm{Cl}_{2}$ before and after titration with $\left[\mathrm{Fe}(\mathrm{Cp})_{2}\right] \mathrm{PF}_{6}$ are shown in Figure 2. The isosbestic points indicate a clean transformation to a single product, which was identified by EPR spectroscopy to 
be a corrole centered radical ([1DMSO] $^{++}$) (see below). The Soret band of $1 \mathrm{DMSO}$ at $382 \mathrm{~nm}$ and Q-band at $574 \mathrm{~nm}$ (Table 2) suggest that the pentacoordinated species is retained in $\mathrm{CH}_{2} \mathrm{Cl}_{2} \cdot{ }^{[10 \mathrm{~b}]}$ The spectrum of $1 \mathrm{DMSO}$ presents similar bands as those of 2Py (Figure 4 and S19-S20 and Table S1 in ref. [2d]), and the oxidized product [1DMSO] ${ }^{\bullet+}$ also presents similar features with [2Py2 $]^{\bullet+}$, notably the Q-band at $714 \mathrm{~nm}$. The Soret band for the former is located at $424 \mathrm{~nm}$ while for the latter it appears at $432 \mathrm{~nm}$.

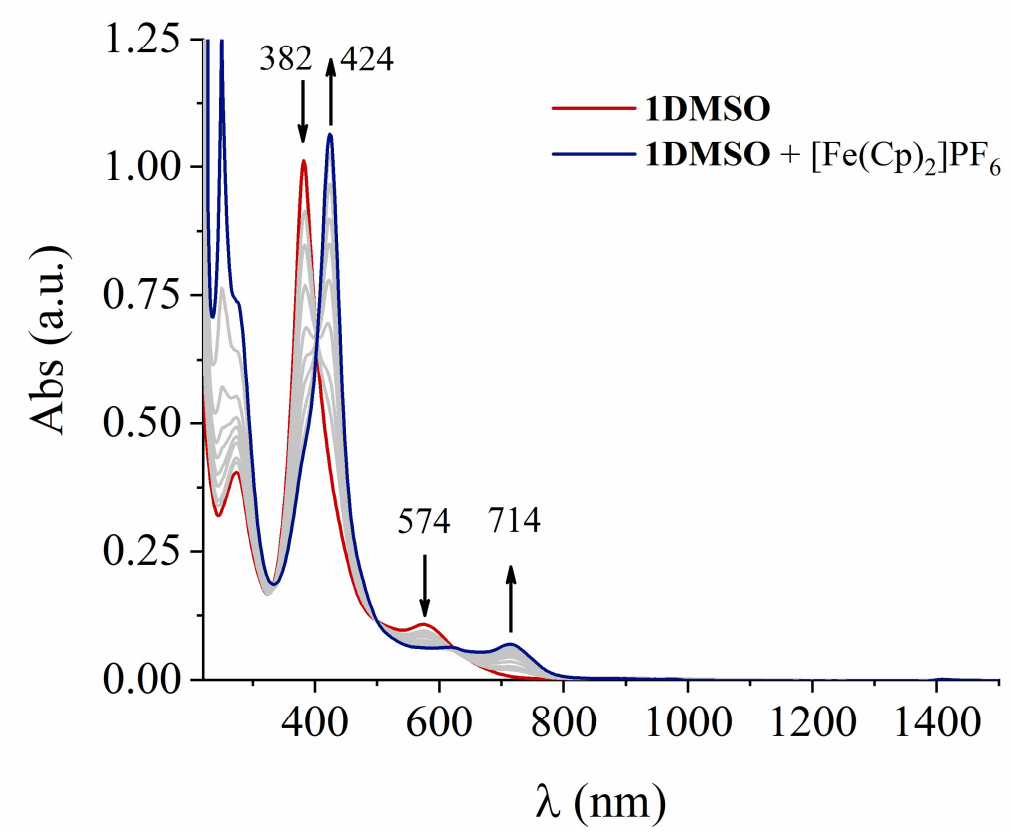

Figure 2. UV-Vis-NIR spectra of $1 \mathrm{DMSO}$ and [1DMSO] ${ }^{\circ+}$, obtained by chemical oxidation with $\left[\mathrm{Fe}(\mathrm{Cp})_{2}\right] \mathrm{PF}_{6}$ in $\mathrm{CH}_{2} \mathrm{Cl}_{2}$.

Table 2. UV-vis-NIR peak positions and normalized absorbance values, in parenthesis, for $1 \mathrm{DMSO}$ and [1DMSO] ${ }^{++}$

\begin{tabular}{ll}
\hline 1DMSO & [1DMSO]•+ \\
$\lambda, \mathbf{n m}($ Abs $)$ & $\lambda, \mathbf{n m}$ (Abs) \\
\hline $382(1.000)$ & $424(1.053)$ \\
$574(0.106)$ & $716(0.067)$ \\
\hline
\end{tabular}

Cyclic voltammetry of 1DMSO in $0.1 \mathrm{M} \mathrm{Bu}_{4} \mathrm{NPF}_{6}$ in MeCN is shown in Figure 3. Six redox processes are observed in total; two reversible and one irreversible oxidations and equal number of reductions are observed. The second, two- 
electron, reduction corresponds to reversible reduction of the nitrophenyl groups, while the third corresponds to irreversible reduction of these groups, as previously discussed by Kadish et al. ${ }^{[7 b]}$ The first oxidation is centered on the ligand, as proven by EPR experiments discussed below. By comparison of the redox potentials of $1 \mathrm{DMSO}$ with those of previously reported $\mathbf{2} \mathbf{P y}_{2}$, it is likely that the second oxidation is corrole centered, while the first reduction is a $\mathrm{Co}(\mathrm{III}) / \mathrm{Co}$ (II) process. EPR results discussed below provide indirect evidence for a metal-centered reduction. The redox potentials of 1DMSO are shown in Table 3, as well as those of $\mathbf{2 P y 2}$. All processes except the third oxidation are anodically shifted for the DMSO-ligated complex compared to the bis(pyridine)ligated ones. This may be partly related with the change in coordination number, but in a very recent work, Nam et al. reported ${ }^{[9]}$ that upon addition of excess acid to $\mathbf{C o}$ (tpfc)Py2 (tpfc = 5,10,15-tris(pentafluorophenyl)corrole and dissociation of both Py ligands, the potential of the first oxidation decreased by $0.03 \mathrm{~V}$ and the potential for the first reduction increased by $0.28 \mathrm{~V}$. Therefore, the $0.25 \mathrm{~V}$ difference between 1DMSO and $2 \mathrm{Py}_{2}$ in their redox potential for the first oxidation seems to be larger than that expected simply by a change in coordination number. This difference could be related with an electronwithdrawing effect of the DMSO ligand, which would be in agreement with the larger $\sigma$-donor character of the Py ligands and the $\pi$-acceptor character of the S-bound DMSO ligand.

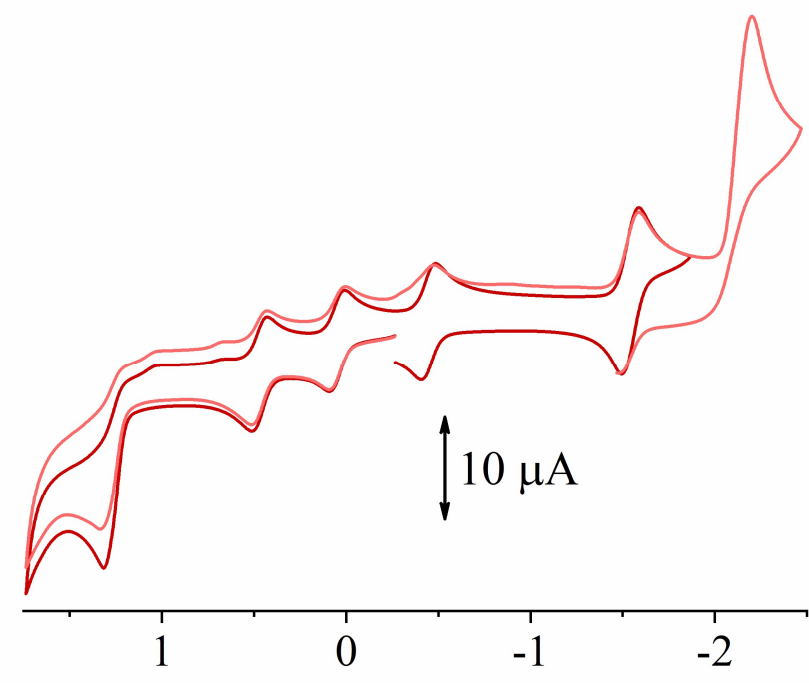

E vs. $\mathrm{FcH}^{+} / \mathrm{FcH}(\mathrm{V})$

Figure 3. Cyclic voltammetry of $1 \mathrm{DMSO}$ in $0.1 \mathrm{M} \mathrm{Bu}_{4} \mathrm{NPF}_{6}$ in DCM, at $50 \mathrm{mV} / \mathrm{s}$. Scan was started in the anodic direction. 
Table 3. Half-Wave and Peak potentials for $1 \mathrm{DMSO}$ and 2Py2 in V.

\begin{tabular}{cccccccc}
\hline Complex & Solvent & $\mathrm{E}_{\mathrm{p}}$ & $\mathrm{E}^{0^{\prime}}$ & $\mathrm{E}^{0^{\prime}}$ & $\mathrm{E}^{0^{\prime}}$ & $\mathrm{E}^{0^{\prime}}$ & $\mathrm{E}_{\mathrm{p}}$ \\
& & $\mathrm{Ox3}$ & $\mathrm{Ox2}$ & $\mathrm{Ox1}$ & $\operatorname{Red1}$ & $\mathrm{Red} 2$ & $\operatorname{Red3}$ \\
\hline 1DMSO & MeCN & $1.32^{\mathrm{a}}$ & 0.47 & 0.05 & -0.45 & -1.54 & - \\
& & & & & & & $2.20^{\mathrm{a}}$ \\
\hline 2Py 2 & MeCN & $1.33^{\mathrm{a}}$ & 0.40 & - & -0.75 & -1.69 & \\
& & & & 0.20 & & & \\
& & & & &
\end{tabular}

[a] Peak potential for irreversible processes.

EPR spectra of $1 \mathrm{DMSO}$ in MeCN before and after oxidation with $\left[\mathrm{Fe}(\mathrm{Cp})_{2}\right] \mathrm{PF}_{6}$ are shown in Figure 4. The isotropic EPR signal after oxidation could be simulated with a g-value of 2.0023 and a small ${ }^{59} \mathrm{Co}$ hyperfine splitting $(I=7 / 2)$ of $13.4 \mathrm{MHz}$ (see Table 4). This signal is very similar to that of [2Py2] ${ }^{\bullet+}$ from our earlier work and corresponds to a corrole-centered radical. DFT calculations of [1DMSO] $]^{\bullet+}$ in MeCN pseudosolvent predict a considerable Co(IV) character, with anisotropic g-values deviating considerably from ge $=2.0023$ and large ${ }^{59} \mathrm{Co}$ hyperfine A-values (see Table 4), in stark contrast with the experimental signal. As discussed in our previous work, ${ }^{[2 d]}$ upon oxidation, the affinity of cobalt corroles for a second apical ligand increases, and so we suspected $\mathrm{MeCN}$ or $\mathrm{PF}_{6}-$ binding could explain the experimental EPR signal.

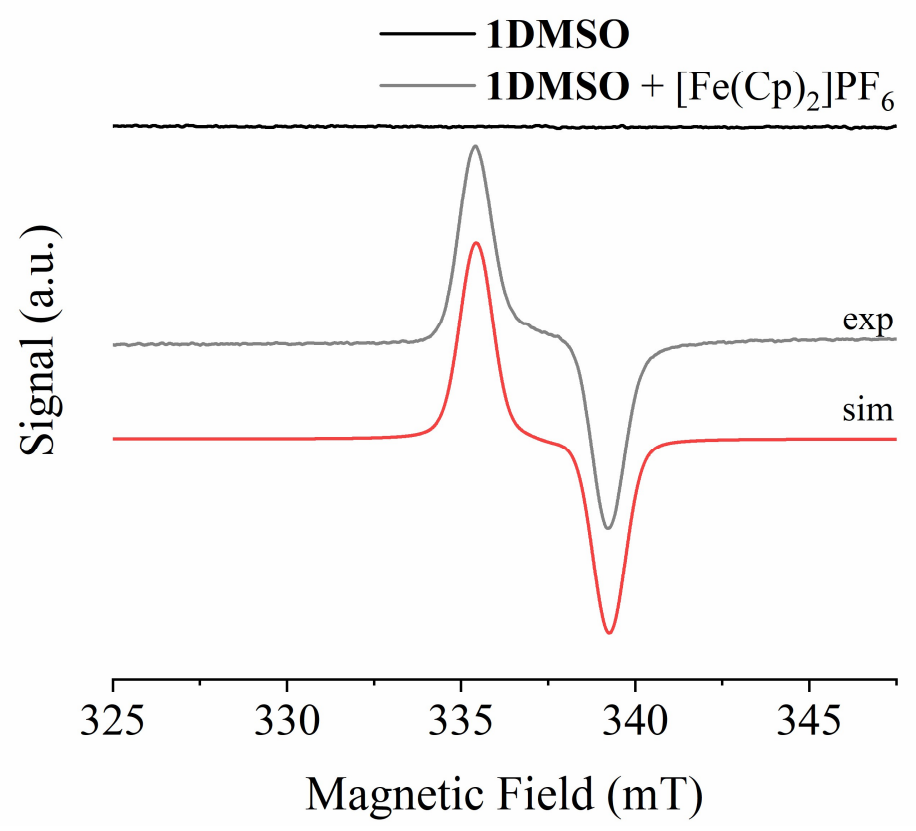


Figure 4. EPR spectra of 1DMSO and [1DMSO] ${ }^{\bullet+}$ obtained by chemical oxidation with $\left[\mathrm{Fe}(\mathrm{Cp})_{2}\right] \mathrm{PF}_{6}$ in $\mathrm{MeCN}$.

For this reason we optimized the geometry of [1DMSO] ${ }^{\bullet+}$ with four explicit MeCN molecules, one of which spontaneously bound to the cobalt center. The calculated gand A-values of this hexacoordinated species ([1DMSO(MeCN)] $\left.{ }^{\bullet+} 3 \mathrm{MeCN}\right)$ are in excellent agreement with the experimental values for [1DMSO] ${ }^{\bullet+}$ in MeCN, strongly supporting the hypothesis of MeCN binding suggested by the EPR signal in Figure 4. The ${ }^{59} \mathrm{Co}$ hyperfine coupling in [1DMSO] ${ }^{\bullet+}(13.4 \mathrm{MHz})$ is slightly but significantly smaller than in [2Py2 $^{\bullet+}(16.4 \mathrm{MHz})$. This suggests a lower spin density on the cobalt ion and a larger one on the corrole ligand, or alternatively on the $\mathrm{S}$ and $\mathrm{O}$ atoms of the DMSO ligand. The spin density plot of the species [1DMSO(MeCN)] • $3 \mathrm{MeCN}$ shows a clear delocalization of the spin density into the meso-4-nitrophenyl substituents, and shows a small but non-negligible spin density on the DMSO ligand. Most of the spin population $(88.5 \%)$ is located in the pyrrole nitrogen and meso-carbon atoms. Some relevant Löwdin spin populations are $-1.5 \%$ on Co, $0.9 \%$ on S and $0.5 \%$ on O, while the values on the pyrrole $\mathrm{N}$ atoms are in the 5-9 \% range and in the 4-nitrophenyl orthocarbons they are around 1.5-2 \% (see Table S1). The qualitative spin density distribution of [1DMSO $\left(\mathrm{MeCN}^{\circ}\right]^{\bullet+} \cdot 3 \mathrm{MeCN}$ is very similar to that of [2Py2] $]^{\bullet+}$ (Figure S10), which also shows delocalization into the meso-4-nitrophenyl substituents. In the latter, the spin population on the cobalt is $-1.2 \%$, on the apical pyridine $\mathrm{N}$ atoms $1 \%$ and on the pyrrole $\mathrm{N}$ atoms it is in the 5-10\% range (Table S2). The overall spin population on the four pyrrole $\mathrm{N}$ atoms plus the three meso-C atoms is $92.4 \%$, slightly higher than in the case of [1DMSO(MeCN)] ${ }^{\bullet+} 3 \mathrm{MeCN}$. However, the calculated ${ }^{59} \mathrm{Co}$ hyperfine splitting for [2Py2] $]^{\bullet+}$ was $-18.4 \mathrm{MHz}$, slightly larger than in the case of [1DMSO$(\mathrm{MeCN})]^{\bullet+}$ - $3 \mathrm{MeCN}$, also following the experimental tendency. These experimental and computational results indicate two things. First, in the case of very small hyperfine couplings it is not straightforward to make assumptions solely based on spin densities/populations, and it is better to calculate the hyperfine splittings. Second, although the EPR signal of these oxidized corrole centered radicals is quite simple, the small amount of information available, in this case the unresolved ${ }^{59} \mathrm{Co}$ hyperfine splitting could, in very particular cases, help deduce if one or more apical ligands have dissociated or exchanged with solvent. Examples of corrole cation radical 
signals with unresolved and well-resolved ${ }^{59} \mathrm{Co}$ hyperfine splittings can be found in references [9] and [2b], respectively.

Table 4. Experimental g-values and hyperfine splittings of [1DMSO $]^{++}$and $[2 \mathrm{Py}]^{0^{++}}$and calculated values for [1DMSO] ${ }^{\circ+}$ [1DMSO(MeCN)] ${ }^{\bullet+} \cdot 3 \mathrm{MeCN}$ and [2Py2 $]^{+*}$.

\begin{tabular}{|c|c|c|c|c|c|}
\hline & \multicolumn{2}{|c|}{ Experimental } & \multicolumn{3}{|c|}{ Calculated } \\
\hline & {$\left[2 \mathrm{Py}_{2}\right]^{\circ+}$} & [1DMSO] $^{\circ+}$ & [1DMSO] $^{\circ+}$ & $\begin{array}{c}{[1 \mathrm{DMSO}(\mathrm{MeCN})]^{++} \cdot 3} \\
\mathrm{MeCN}\end{array}$ & {$\left[2 \mathrm{Py}_{2}\right]^{\circ+}$} \\
\hline $\begin{array}{c}\text { g- } \\
\text { value }\end{array}$ & 2.0023 & 2.0023 & $1.99,2.153,2.179$ & 2.0011 & 2.0015 \\
\hline $\begin{array}{l}{ }^{59} \mathrm{Co} \\
(\mathrm{MHz})\end{array}$ & 16.4 & 13.4 & $597,260,268$ & -16.23 & -18.4 \\
\hline
\end{tabular}

We also performed EPR studies of chemically reduced $1 \mathrm{DMSO}$ in $\mathrm{CH}_{2} \mathrm{Cl}_{2}$, using cobaltocene $\left(\mathrm{Co}(\mathrm{Cp})_{2}\right)$ as chemical reductant (see Figure $\left.\mathrm{S6}\right)$. The spectrum showed a sharp radical signal visible from room temperature down to $-150^{\circ} \mathrm{C}$, which at first sight appeared to indicate a ligand centered reduction. However, there have been many reports of metal centered reductions on cobalt corroles. ${ }^{[2 d, 3 a, 19]}$ Some of these spectra were acquired at liquid He temperatures and showed very anisotropic EPR spectra. Therefore, we decided to add a drop of Py to the sample (under Schlenk conditions) to see if a similar spectrum as the one previously reported for reduced $2 \mathrm{Py}$ was observed. ${ }^{[2 d]}$ This afforded a spectrum essentially identical to the one reported previously by us, corresponding to a low-spin Co(II) species, in which the ${ }^{14} \mathrm{~N}$ superhyperfine splitting to the pyridine nitrogen can be clearly observed (Figure S6, blue trace). The sharp radical signal did not change intensity upon addition of $\mathrm{Py}$, and the doubly integrated intensity of this signal is actually minor compared to the anisotropic low-spin $\mathrm{Co}$ (II) signal. As we have used an excess of $\mathrm{Co}(\mathrm{Cp})_{2}$, it is likely that this signal arises from a reduction side-reaction. It has been shown ${ }^{[10 b]}$ that DMSO dissociates from some cobalt corroles upon reduction. Therefore, our hypothesis explaining the EPR experimental results is that upon reduction DMSO dissociated, producing a fourcoordinate $\mathrm{Co}(\mathrm{II})$ centered radical species with an EPR signal too broad to be observed at liquid $\mathrm{N}_{2}$ temperature. ${ }^{[19]}$ Upon addition of $\mathrm{Py}$ the pentacoordinated [Co(II)corrole(Py)]- species formed, producing the EPR signal shown in Figure S6. These results would support a metal centered reduction. 


\section{DFT and WFT electronic structure calculations}

Geometry optimization of 1DMSO using the broken-symmetry approach revealed that the open-shell singlet state is located $2428.1 \mathrm{~cm}^{-1}(29.0 \mathrm{~kJ} / \mathrm{mol})$ lower in energy than the triplet state, while the energy of the closed-shell singlet was found to be $676.5 \mathrm{~cm}^{-}$ ${ }^{1}$ above the open-shell. The spin density plot of the open-shell state is shown in Figure S7. An open-shell ground state was proposed by Kadish et al. ${ }^{[10 b, 11]}$ for mono-DMSO bound Co(III)corroles, based on UV-vis and electrochemical results, as well as computational results assuming an O-bound DMSO. In the case of 1DMSO, X-ray diffraction studies unequivocally show that the DMSO ligand is S-bound in the solid state, which is also supported by IR measurements. S-bound DMSO can act as a $\sigma-$ donor and $\pi$-acceptor and thus is expected to be a strong ligand. This would favor a low-spin Co(III) central metal, which would require a closed-shell singlet description of the complex. This was not predicted by DFT, which supported the non-innocent description proposed so far. However, as DFT may sometimes give incorrect spin-state energetics in transition metal ions, we decided to conduct correlated wavefunction theory (WFT) calculations using the complete-active space self-consistent field (CASSCF) method, together with $\mathrm{N}$-electron valence second order perturbation theory (NEVPT2), to account for dynamical correlations. These calculations were performed using ORCA, ${ }^{[20]}$ with an active space comprising 10 electrons distributed in 9 orbitals, i.e. the five metal $3 d$ orbitals and the corrole Gouterman orbitals (see Figure 5 and Figures S11 and S12), and 10 triplet and 30 singlet roots were included. The terms HOMO and LUMO refer to the occupations of the orbitals in the free-base corrole. 

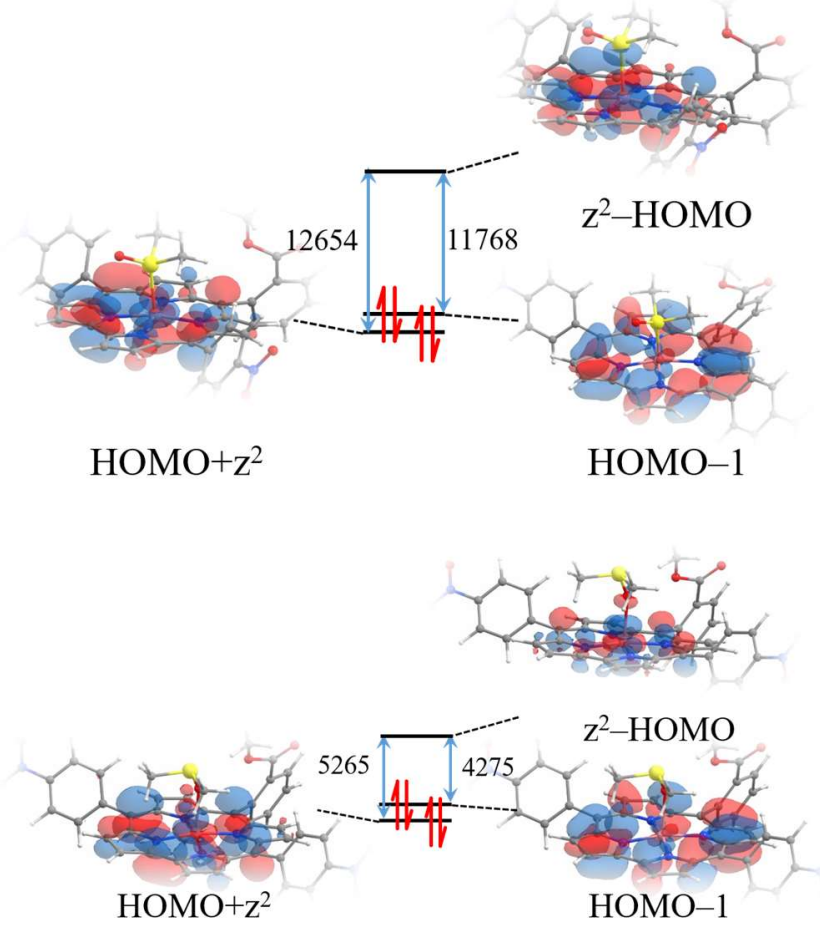

Figure 5. Energy diagram and orbital isosurfaces for the frontier orbitals in 1DMSO (left) and 1(O-DMSO) (right). Energy differences are given in $\mathrm{cm}^{-1}$.

As can be seen in Figure 5, the first unoccupied orbital is an antibonding combination of the metal $d z^{2}$ and one of the corrole $\pi$ orbitals, similar to the HOMO of the free-base corrole. This orbital, which we will designate for short as $\left(d z^{2}-\mathrm{HOMO}\right)$ is $\sigma$-antibonded with the $S$ lone pair in DMSO. This $\sigma$ interaction raises the energy of the $d z^{2}-\mathrm{HOMO}$ orbital, stabilizing the closed shell ground state. There is a slight amount of orbital amplitude on the DMSO O-atom which could suggest a small backbonding effect, but this appears to be much less significant than the donor effect of the $S$ lone pair.

In the case of the O-bound structure (1(O-DMSO)), calculations also predicted a closed-shell ground state, but with a gap between the HOMO-1 and $d z^{2}-\mathrm{HOMO}$ smaller than half of the S-bound case. Table 5 summarizes the energies and orbital configurations for the lowest energy states of singlet and triplet multiplicity for 1DMSO and 1(O-DMSO). For 1DMSO the ground state obtained by CASSCF calculations corresponds to a closed shell configuration, and this is also the ground state after applying perturbative corrections (NEVPT2), to account for dynamic correlation. This closed-shell ground state is a mixture of mainly two configuration state functions (CSFs) with only doubly-occupied and empty orbitals, and corresponds to a 
[Co(III)corrole ${ }^{3-}$ (DMSO)] description. The closest lying singlet state with an open-shell character lies $5614.9 \mathrm{~cm}^{-1}$ above the ground state, and can be described as a mixture of two configurations, one with an unpaired electron in the $d z^{2}-\mathrm{HOMO}$ and another in the HOMO-1 orbital, and the other with unpaired electrons in the HOMO+ $d z^{2}$ and HOMO-1 orbitals, corresponding to a [Co(II)corrole $\left.{ }^{\bullet-}(\mathrm{DMSO})\right]$ description. This state is the one that more closely resembles the open-shell singlet predicted by DFT calculations. The first excited state of triplet character lies $2141.6 \mathrm{~cm}^{-1}$ above the ground state, quite lower than the open-shell singlet, and is mainly described by one configuration with unpaired electrons in the $\mathrm{HOMO}+d z^{2}$ and $d z^{2}-\mathrm{HOMO}$ orbitals. The WFT calculations thus contradict DFT results, establishing the role of the corrole ligand as innocent for the complex studied here. In the case of 1(O-DMSO), CASSCF calculations predict a triplet to be the ground state, but the NEVPT2 corrected energies predict the closed-shell singlet again to be the ground state, followed by a triplet state higher in energy by $919.6 \mathrm{~cm}^{-1}$ and then the open-shell singlet at $4840.7 \mathrm{~cm}^{-1}$ above the closed-shell singlet. This open-shell singlet is similar to the one predicted by DFT calculations to be the ground state, and whose spin density is shown in Figure S8. Again the order of the states according to CASSCF/NEVPT2 contradicts the DFT results.

Table 5. State energies and configurations of 1DMSO and 1(O-DMSO) obtained from DFT and CASSCF/NEVPT2 calculations. For relevant states the orbital configurations are given next to the Configuration State Function (CSF) occupation patterns.

\begin{tabular}{|c|c|c|c|c|c|c|c|}
\hline & & 1DMSO & & Energ & $\left(\mathrm{cm}^{-1}\right)$ & & \\
\hline State & Configuration & Orbital Configuration $^{[a]}$ & $2 \mathrm{~S}+1$ & CASSCF & $\overline{\text { NEVPT2 }}$ & DFT & Label $^{[b]}$ \\
\hline 0 & $\begin{array}{l}0.58[222220000]+ \\
0.33[222202000]\end{array}$ & $\begin{array}{l}+\quad 0.58\left[(\mathrm{xy})^{2}(\mathrm{yz})^{2}(\mathrm{xz})^{2}(\mathrm{~h}-1)^{2}(\mathrm{~h})^{2}\right]+ \\
0.33\left[(\mathrm{xy})^{2}(\mathrm{yz})^{2}(\mathrm{xz})^{2}(\mathrm{~h}-1)^{2}\left(\mathrm{z}^{2}\right)^{2}\right]\end{array}$ & 1 & 0 & 0 & 676.5 & $\mathrm{~S}$ \\
\hline 1 & $\begin{array}{l}0.57[222121000]+ \\
0.31[222112000]\end{array}$ & $\begin{array}{l}+\quad 0.57\left[(\mathrm{xy})^{2}(\mathrm{yz})^{2}(\mathrm{xz})^{2}(\mathrm{~h}-1)^{1}(\mathrm{~h})^{2}\left(\mathrm{z}^{2}\right)^{1}\right]+ \\
0.31\left[(\mathrm{xy})^{2}(\mathrm{yz})^{2}(\mathrm{xz})^{2}(\mathrm{~h}-1)^{1}(\mathrm{~h})^{1}\left(\mathrm{z}^{2}\right)^{2}\right]\end{array}$ & 1 & 4256.8 & 5614.9 & 0 & oss \\
\hline 2 & $\begin{array}{l}0.41[221221000]+ \\
0.38[221212000]\end{array}$ & & 1 & 8629.4 & 10696.5 & & \\
\hline 3 & $\begin{array}{l}0.42[212221000]+ \\
0.40[212212000]\end{array}$ & & 1 & 9195.4 & 11600.7 & & \\
\hline 4 & $\begin{array}{l}0.65[221122000]+ \\
0.11[222022000]\end{array}$ & & 1 & 12050.9 & 15035.9 & & \\
\hline 5 & $0.78[212122000]$ & & 1 & 12842.6 & 16331.6 & & \\
\hline 2 & $0.92[222211000]$ & $0.92\left[(x y)^{2}(y z)^{2}(x z)^{2}(h-1)^{2}(h)^{1}\left(z^{2}\right)^{1}\right]$ & 3 & 1171.2 & 2141.6 & 2428.1 & $\mathrm{~T}$ \\
\hline
\end{tabular}




\begin{tabular}{|c|c|c|c|c|c|c|c|}
\hline \multirow{2}{*}{0} & $0.30[221220100]+$ & + & \multirow{2}{*}{3} & \multirow[t]{2}{*}{596.2} & \multirow[t]{2}{*}{9354.9} & & \\
\hline & $0.23[221211100]$ & & & & & & \\
\hline \multirow{2}{*}{4} & $0.30[222121000]+$ & + & \multirow{2}{*}{3} & \multirow[t]{2}{*}{4060.7} & \multirow[t]{2}{*}{9546.7} & & \\
\hline & $0.22[221121100]$ & & & & & & \\
\hline \multirow{2}{*}{1} & $0.25[122220100]+$ & + & \multirow{2}{*}{3} & \multirow[t]{2}{*}{794.1} & \multirow[t]{2}{*}{9780.4} & & \\
\hline & $0.19[122211100]$ & & & & & & \\
\hline \multirow{3}{*}{5} & $0.28[222121000]+$ & \multirow[t]{2}{*}{+} & \multirow{2}{*}{3} & \multirow[t]{2}{*}{4281.98} & \multirow[t]{2}{*}{9820.2} & & \\
\hline & $0.20[221121100]$ & & & & & & \\
\hline & & 1(O-DMSO) & & \multicolumn{3}{|c|}{ Energy $\left(\mathrm{cm}^{-1}\right)$} & \\
\hline State & Configuration & Orbital Configuration $^{[a]}$ & $2 S+1$ & CASSCF & NEVPT2 & DFT & Label $^{[b]}$ \\
\hline \multirow[t]{2}{*}{0} & $0.44[222220000]+$ & $0.44\left[(x y)^{2}(y z)^{2}(x z)^{2}(h-1)^{2}(h)^{2}\right]+$ & 1 & 2074.4 & 0 & 1418 & $S^{[c]}$ \\
\hline & $0.28[222202000]$ & $0.28\left[(x y)^{2}(y z)^{2}(x z)^{2}(h-1)^{2}\left(z^{2}\right)^{2}\right]$ & & & & & \\
\hline \multirow[t]{2}{*}{1} & $0.69[222121000]+$ & $0.69\left[(x y)^{2}(y z)^{2}(x z)^{2}(h-1)^{1}(h)^{2}\left(z^{2}\right)^{1}\right]+$ & 1 & 5351.0 & 4840.7 & 0 & Oss \\
\hline & $0.20[222112000]$ & $0.20\left[(x y)^{2}(y z)^{2}(x z)^{2}(h-1)^{1}(h)^{1}\left(z^{2}\right)^{2}\right]$ & & & & & \\
\hline \multirow[t]{2}{*}{2} & $0.55[221212000]+$ & & 1 & 7838.6 & 6298.9 & & \\
\hline & $0.26[221221000]$ & & & & & & \\
\hline 3 & $0.92[222211000]$ & $0.92\left[(x y)^{2}(y z)^{2}(x z)^{2}(h-1)^{2}(h)^{1}\left(z^{2}\right)^{1}\right]$ & 3 & 2535.5 & 919.6 & 627 & $T$ \\
\hline \multirow[t]{2}{*}{8} & $0.70[222121000]+$ & & 3 & 5315.3 & 4833.3 & & \\
\hline & $0.20[222112000]$ & & & & & & \\
\hline \multirow[t]{2}{*}{0} & $0.36[221211100]+$ & & 3 & 0 & 5380.8 & & \\
\hline & $0.24[221220100]$ & & & & & & \\
\hline
\end{tabular}

[a] For simplicity, the label $z^{2}$ refers to the molecular orbital composed of the mixture of the metal $3 d z^{2}$ and the corrole HOMO where the $3 d z^{2}$ predominates, while the term $h$ refers to the mixture of the same orbitals where the HOMO predominates. [b] $\mathrm{S}$ (singlet) indicates a true singlet state with zero-spin density everywhere, OSS (openshell singlet), indicates a state with antiferromagnetically coupled spins and a net $\mathrm{Ms}$ $=0$ spin projection, with non-zero spin densities of opposite signs in different regions of the molecule. T indicates a triplet state. [c] Although the requested multiplicity in this calculation was 1 , the self-consistent field converged to an open-shell singlet state, although more localized in the metal than the one resulting from the broken symmetry calculation.

CASSCF calculations are more sophisticated than DFT, but they are also complicated by the choice of active space, and state averaging over many energy roots. For this reason, it is important to verify, when possible, if the results from the calculations predict any experimental properties which could help validate them. As the UV-Vis-NIR spectra of metallocorroles is very sensitive to differences in coordination number, oxidation and spin state, we calculated the absorption bands of 1DMSO by CASSCF/NEVPT2, and these are listed in Table 6. Besides the small 20-30 nm $\left(\sim 1200-900 \mathrm{~cm}^{-1}\right)$ red-shift of the calculated transitions compared to the experimental 
ones, the agreement with experiment is quite good, especially in the intensity ratio between Soret and Q-bands. The calculated band positions and intensities for 1(0DMSO) are considerably more red-shifted and the intensity pattern doesn't match as well the experimental spectrum. Both simulated and experimental spectra for 1DMSO are shown in Figure S13.

Table 6. CASSCF/NEVPT2 calculated bands for 1DMSO and 1(O-DMSO), and experimental absorption bands for 1DMSO in $\mathrm{CH}_{2} \mathrm{Cl}_{2}$.

\begin{tabular}{lllll}
\hline Exp & 1DMSO & \multicolumn{3}{l}{ 1(O-DMSO) } \\
\hline$\lambda, \mathbf{n m}$ & $\lambda, \mathbf{n m}$ & $\begin{array}{l}\text { Energy } \\
\left(\mathbf{c m}^{-1}\right)\end{array}$ & $\begin{array}{l}\lambda, \mathbf{n m} \\
\text { (fosc) }\end{array}$ & $\begin{array}{l}\text { Energy } \\
\left(\mathbf{c m}^{-1}\right)\end{array}$ \\
\hline 382 & 371.5 & 26914.8 & 449.7 & 22237.9 \\
$(1.000)$ & $(0.356)$ & & $(0.375)$ & \\
& 387.7 & 25795.6 & 488.6 & 20466.5 \\
& $(0.200)$ & & $(0.285)$ & \\
& 401.6 & 24901.8 & & \\
& $(0.628)$ & & & \\
& 411.2 & 24319.1 & & \\
& $(0.238)$ & & & 14703.9 \\
574 & 548.0 & 18248.8 & 594.0 & 16835.4 \\
$(0.106)$ & $(0.017)$ & & $(0.064)$ & \\
& 604.3 & 16547.2 & 680.1 & \\
& $(0.089)$ & & $(0.121)$ & \\
\hline
\end{tabular}

The agreement between the calculated and experimental UV-Vis-NIR spectrum of 1DMSO provides validation for the electronic structure description obtained by CASSCF calculations. These suggest that the $\sigma$-donor effect of the $S$ atom of DMSO is responsible in lifting the energy of the $d z^{2}$ orbital, thus favoring a closed shell lowspin Co(III) configuration, and no appreciable $\pi$-backbonding effects are apparent from observation of the active orbitals, in agreement with the discussion by Scheidt et al. ${ }^{[15]}$ The CASSCF/NEVPT2 calculations presented here are among the few examples of multireference calculations applied to metallocorroles ${ }^{[21]}$ and are, to the best of our 
knowledge, the first ones applied to a full cobalt corrole, including its meso-substituents and apical ligand. ${ }^{[22]}$

\section{Conclusion}

We have synthesized and report for the first time the molecular structure of an S-bound DMSO complex of a Co(III) corrole (1DMSO), obtained by single-crystal X-ray diffraction. We analyzed its redox and UV-Vis-NIR and EPR spectroscopic properties experimentally and rationalized the latter using DFT and ab initio calculations. Bond distances, as well as multiconfigurational ab initio calculations show that the ground state of 1DMSO can be described as a closed-shell low-spin Co(III) corrole, where the corrole acts as an innocent ligand. Furthermore, the calculations show that the reason for the low-spin ground state is the elevation in energy of the Co(III) $d z^{2}$ orbital due to a large $\sigma$-donor effect of the $S$ atom of DMSO, and not to a back-bonding effect. The fact that S-bound DMSO favors a low-spin $\mathrm{Co}$ (III) configuration, together with the short Co-S distance (2.1331(9) $\AA$ ) suggests a strong Co-S bond. This opens interesting possibilities for immobilization of cobalt(III) corroles on sulfoxide functionalized surfaces, producing pentacoordinated complexes with an available apical site on the cobalt ion, which could be used in catalysis.

\section{Experimental Section}

\section{Synthesis}

Free base corrole $\mathrm{H}_{3} \mathrm{~L} 1$ was synthesized as described previously. [2d] Metallation was performed following the method of Kadish et al., ${ }^{[10 b, 12]}$ by addition of 1.2 equivalents of Co(II)(acetate) 2 tetrahydrate to 1 equivalent of $\mathrm{H}_{3} \mathrm{~L} 1$ in DMSO $(20 \mathrm{ml}$ per $100 \mathrm{mg}$ of free base corrole). The solution was heated to $80^{\circ} \mathrm{C}$ for about one hour under an $\mathrm{Ar}$ stream, during which the solution changed from green to brownish-red. After the reaction was complete by TLC, heat was removed and the solution was let cool down to slightly above room temperature. Then it was poured into approximately $200 \mathrm{ml}$ of cold nearly-saturated $\mathrm{NaCl}$ solution in distilled $\mathrm{H}_{2} \mathrm{O}$, and let stand for one hour. The dark red solid was separated from the aqueous solution by paper filtration, and washed extensively with distilled water. The solid was left drying overnight and then it was dissolved in $\mathrm{DCM}$, using $\mathrm{MeOH}$ to solubilize the aqueous humidity still in the sample. The dark-red solution was concentrated and dried under reduced pressure in a rotary evaporator, then it was dissolved in DCM and layered with $n$-hexane. In a few days 
large red plates crystallized from the mixture. Some of these crystals were fragile and seemed to degrade when removed from the mother liquor, but some crystals could be transferred to mineral oil and used for X-ray diffraction studies.

Analytical data for 1DMSO: ${ }^{1} \mathrm{H}$ NMR (700 MHz, DMSO-d6, Figures S3 and S4): $\delta / p p m$ $=8.88\left(\mathrm{~d}, 2 \mathrm{H},{ }^{3} \mathrm{JHH}=4.4 \mathrm{~Hz}\right.$, pyrrole B-H), $8.56\left(\mathrm{dd}, 4 \mathrm{H},{ }^{3} \mathrm{JHH}_{\mathrm{HH}}=8.3 \mathrm{~Hz},{ }^{4} \mathrm{JHH}_{\mathrm{HH}}=4.8 \mathrm{~Hz}\right.$, $\left.\mathrm{m}-\mathrm{NO}_{2} \mathrm{Ph}\right), 8.44\left(\mathrm{~d}, 2 \mathrm{H},{ }^{3} \mathrm{JHH}_{\mathrm{HH}}=8.1 \mathrm{~Hz}, \mathrm{o}-\mathrm{NO}_{2} \mathrm{Ph}\right), 8.37\left(\mathrm{~d}, 2 \mathrm{H},{ }^{3} \mathrm{JHH}_{\mathrm{HH}}=8.1 \mathrm{~Hz}, \mathrm{o}-\mathrm{NO}_{2} \mathrm{Ph}\right.$ ), $8.21\left(\mathrm{dd}, 1 \mathrm{H},{ }^{3} \mathrm{~J}_{\mathrm{HH}}=7.8 \mathrm{~Hz},{ }^{4} \mathrm{~J}_{\mathrm{HH}}=1.8 \mathrm{~Hz}, 2-\mathrm{CO}_{2} \mathrm{MePh}\right), 8.17\left(\mathrm{~d}, 2 \mathrm{H},{ }^{3} \mathrm{JHH}_{\mathrm{HH}}=4.7 \mathrm{~Hz}\right.$, pyrrole $\beta-H), 8.16\left(d, 2 \mathrm{H},{ }^{3} \mathrm{JHH}_{\mathrm{HH}}=4.4 \mathrm{~Hz}\right.$, pyrrole $\left.ß-\mathrm{H}\right), 7.96\left(\mathrm{dd}, 1 \mathrm{H},{ }^{3} \mathrm{~J}_{\mathrm{HH}}=7.1 \mathrm{~Hz},{ }^{4} \mathrm{~J}_{\mathrm{HH}}\right.$ $\left.=1.6 \mathrm{~Hz}, 5-\mathrm{CO}_{2} \mathrm{MePh}\right), 7.88\left(\mathrm{dd}, 1 \mathrm{H},{ }^{3} \mathrm{JHH}_{\mathrm{HH}}=7.6 \mathrm{~Hz},{ }^{4} \mathrm{~J}_{\mathrm{HH}}=1.6 \mathrm{~Hz}, 3-\mathrm{CO}_{2} \mathrm{MePh}\right), 7.84$ (dd, $\left.1 \mathrm{H},{ }^{3} \mathrm{JHH}_{\mathrm{HH}}=7.5 \mathrm{~Hz},{ }^{4} \mathrm{~J}_{\mathrm{HH}}=1.7 \mathrm{~Hz}, 4-\mathrm{CO}_{2} \mathrm{MePh}\right), 7.86\left(\mathrm{~d}, 2 \mathrm{H},{ }^{3} \mathrm{~J}_{\mathrm{HH}}=4.6 \mathrm{~Hz}\right.$, pyrrole ß-H). IR (solid): Uso $=1012.2,983.0 \mathrm{~cm}^{-1}$. UV-Vis-NIR $\left(\mathrm{CH}_{2} \mathrm{Cl}_{2}\right): \lambda, \mathrm{nm}$ (Abs, a.u.): 382 (1.000), 574 (0.106).

\section{Instrumentation}

Cyclic voltammetry measurements were performed in a one-compartment threeelectrode Schlenk-type cell, equipped with a $3 \mathrm{~mm}$ Glassy carbon disk working electrode, a Pt wire counterelectrode and an Ag pseudoreference electrode. Ferrocene $(\mathrm{FcH})$ was used as an internal potential calibrant and potentials are referenced to the $\mathrm{FcH}^{+} / \mathrm{FcH}$ couple. Degassed electronic grade $\mathrm{MeCN}$, freshly distilled from $\mathrm{CaH}_{2}$, was used as a solvent, and dry $\mathrm{Bu}_{4} \mathrm{NPF}_{6}$ was used as supporting electrolyte. Measurements were performed using a PalmSens4 potentiostat. Atenuated Total Reflection (ATR) IR measurements were peformed on a Thermo Scientific Nicolet iS5 FTIR spectrometer. UV-Vis-NIR spectra were acquired on a standard $1 \mathrm{~cm}$ optical path quartz cuvette using a J\&M Tidas UV-Vis-NIR spectrometer. EPR measurementes were performed in a Magnettech MS- 5000 benchtop EPR spectrometer. Simulations were performed using the EasySpin package ${ }^{[23]}$ running in Matlab R2020a. ${ }^{1} \mathrm{H}$ NMR spectra were acquired in a Bruker Avancelll HD700MHz spectrometer.

\section{X-ray crystallography.}

X-ray data were collected at $140(2) \mathrm{K}$ on a Bruker Kappa Apexll Duo diffractometer using mirror-monochromated Mo Ka radiation $(\lambda=0.71073 \AA)$. Images were collected by combination of $\omega$ - and $\varphi$-scan techniques and scaled and reduced using the APEX2 software. ${ }^{[24]}$ The structures were solved by intrinsic phasing using SHELXT-2015 [25] and refined using SHELXL ${ }^{[26]}$ by full-matrix least squares, refining on $\mathrm{F}^{2}$, using ShelXLe. ${ }^{[27]}$ Non-hydrogen atoms were refined anisotropically, and $\mathrm{H}$ atoms were 
included using a riding model. Disorder in the solvation $n$-hexane molecule was modeled by applying EADP constraints and ISOR restraints to the $n$-hexane $\mathrm{C}$ atoms. CCDC 2057883 contains the supplementary crystallographic data for this paper. These data can be obtained free of charge from The Cambridge Crystallographic Data Centre.

\section{Electronic Structure Calculations}

All electronic structure calculations were performed with the ORCA electronic structure package, versions 4.2.0 and 4.2.1. [20b] The geometries of all species were optimized using the PBE0 functional, ${ }^{[28]}$ the def2-SVP basis sets on all atoms except for $\mathrm{Co}$, for which the def2-TZVP basis set was used. ${ }^{[29]}$ Solvation was taken into account using the CPCM model ${ }^{[30]}$ using $\mathrm{MeCN}$ as solvent, and dispersion corrections were included using the D3 dispersion correction model. ${ }^{[1]}$ The resolution-of-the-identity (RI) approximation, ${ }^{[32]}$ with matching basis sets, ${ }^{[33]}$ as well as the RIJCOSX approximation (combination of RI and chain-of-spheres algorithm for exchange integrals) were used to reduce the time of calculations. Numerical or analytical frequencies calculations were used in order to check that the optimized structures were local minima and to obtain Gibbs free enthalpies. IR frequencies were calculated at the reported theory level, and also using def2-TZVP on all atoms. The Broken Symmetry approach, as implemented in ORCA, was used to optimize the geometries of open-shell species, and estimate their singlet-triplet gap. Complete active space self-consistent field (CASSCF) calculations, followed by perturbative NEVPT2 (N-electron valence second order perturbation) corrections, were performed on the optimized geometries of 1DMSO and O-bound 1(O-DMSO). The active space included 10 electrons distributed in 9 orbitals (CAS $(10,9))$, and calculations included 10 triplet and 30 singlet roots. In order calculate the UV-vis transitions of $1 \mathrm{DMSO} 80$ singlet roots were included. The active space included the five cobalt $3 d$ orbitals and the corrole Gouterman orbitals.

\section{Acknowledgements}

This work was possible due to funds provided by the Alexander von Humboldt Foundation (Postdoctoral stipend to N.I.N.) and the University of Stuttgart. N.I.N., S.E.V., and F.D. are members of CONICET. The computational facilities of ZEDAT, FU Berlin, are kindly acknowledged, as well as the Pirayu Cluster, financed by ASACTEI, Provincia de Santa Fe, Argentina. 


\section{References}

[1] a) A. Johnson and I. Kay, J. Chem. Soc. 1965, 1620-1629; b) A. W. Johnson and I. Kay, Proc. R. Soc. London, Ser. A 1965, 288, 334-341.

[2] a) D. K. Dogutan, R. McGuire Jr and D. G. Nocera, J. Am. Chem. Soc. 2011, 133, 9178-9180; b) W. Sinha, A. Mizrahi, A. Mahammed, B. Tumanskii and Z. Gross, Inorg. Chem. 2018, 57, 478-485; c) W. Sinha, A. Mahammed, N. Fridman and Z. Gross, ACS Catalysis 2020, 10, 3764-3772; d) N. I. Neuman, U. Albold, E. Ferretti, S. Chandra, S. Steinhauer, P. Rößner, F. Meyer, F. Doctorovich, S. E. Vaillard and B. Sarkar, Inorg. Chem. 2020, 59, 16622-16634.

[3] a) A. Mahammed, B. Mondal, A. Rana, A. Dey and Z. Gross, Chem. Commun. 2014, 50, 2725-2727; b) H. Lei, A. Han, F. Li, M. Zhang, Y. Han, P. Du, W. Lai and R. Cao, Phys. Chem. Chem. Phys. 2014, 16, 1883-1893; c) M. A. Morales Vásquez, M. Hamer, N. I. Neuman, A. Y. Tesio, A. Hunt, H. Bogo, E. J. Calvo and F. Doctorovich, ChemCatChem 2017, 9, 3259-3268.

[4] a) K. M. Kadish, J. Shen, L. Frémond, P. Chen, M. El Ojaimi, M. Chkounda, C. P. Gros, J.-M. Barbe, K. Ohkubo and S. Fukuzumi, Inorg. Chem. 2008, 47, 6726-6737; b) K. M. Kadish, L. Frémond, Z. Ou, J. Shao, C. Shi, F. C. Anson, F. Burdet, C. P. Gros, J.-M. Barbe and R. Guilard, J. Am. Chem. Soc. 2005, 127, 5625-5631; c) W. Schöfberger, F. Faschinger, S. Chattopadhyay, S. Bhakta, B. Mondal, J. A. Elemans, S. Müllegger, S. Tebi, R. Koch and F. Klappenberger, Angew. Chem. 2016, 128, 2396-2401.

[5] a) S. Gonglach, S. Paul, M. Haas, F. Pillwein, S. S. Sreejith, S. Barman, R. De, S. Müllegger, P. Gerschel and U.-P. Apfel, Nat. Commun. 2019, 10, 1-10; b) J.

Grodkowski, P. Neta, E. Fujita, A. Mahammed, L. Simkhovich and Z. Gross, J. Phys. Chem. A 2002, 106, 4772-4778.

[6] S. Ganguly, J. Conradie, J. Bendix, K. J. Gagnon, L. J. McCormick and A. Ghosh, J. Phys. Chem. A 2017, 121, 9589-9598.

[7] a) R. Guilard, C. P. Gros, F. Bolze, F. Jérôme, Z. Ou, J. Shao, J. Fischer, R. Weiss and K. M. Kadish, Inorg. Chem. 2001, 40, 4845-4855; b) X. Jiang, M. L. Naitana, N. Desbois, V. Quesneau, S. Brandès, Y. Rousselin, W. Shan, W. R. Osterloh, V. Blondeau-Patissier and C. P. Gros, Inorganic chemistry 2018, 57, 12261241; c) P. B. Hitchcock and G. M. McLaughlin, J. Chem. Soc., Dalton Trans. 1976, 1927-1930; d) S. Ganguly, D. Renz, L. J. Giles, K. J. Gagnon, L. J. McCormick, J. Conradie, R. Sarangi and A. Ghosh, Inorg. Chem. 2017, 56, 14788-14800. 
[8] a) V. A. Adamian, F. D'Souza, S. Licoccia, M. L. Di Vona, E. Tassoni, R.

Paolesse, T. Boschi and K. M. Kadish, Inorganic Chemistry 1995, 34, 532-540; b) A. Mahammed, I. Giladi, I. Goldberg and Z. Gross, Chem. Eur. J. 2001, 7, 4259-4265.

[9] A. Rana, Y.-M. Lee, X. Li, R. Cao, S. Fukuzumi and W. Nam, ACS Catalysis 2021, 3073-3083.

[10] a) V. Quesneau, W. Shan, N. Desbois, S. Brandès, Y. Rousselin, M. Vanotti, V. Blondeau-Patissier, M. Naitana, P. Fleurat-Lessard and E. Van Caemelbecke, Eur. J. Inorg. Chem. 2018, 2018, 4265-4277; b) X. Jiang, W. Shan, N. Desbois, V.

Quesneau, S. Brandès, E. Van Caemelbecke, W. Osterloh, V. Blondeau-Patissier, C. Gros and K. M. Kadish, New J. Chem. 2018, 42, 8220-8229.

[11] W. R. Osterloh, N. Desbois, V. Quesneau, S. Brandès, P. Fleurat-Lessard, Y. Fang, V. Blondeau-Patissier, R. Paolesse, C. P. Gros and K. M. Kadish, Inorg. Chem. 2020, 59, 8562-8579.

[12] W. R. Osterloh, V. Quesneau, N. Desbois, S. p. Brandès, W. Shan, V. BlondeauPatissier, R. Paolesse, C. P. Gros and K. M. Kadish, Inorg. Chem. 2019, 59, 595611.

[13] a) K. Venkatasubbaiah, X. Zhu, E. Kays, K. I. Hardcastle and C. W. Jones, ACS Catalysis 2011, 1, 489-492; b) A. F. Alcântara, L. A. Fontana, V. H. Rigolin, Y. F. Andrade, M. A. Ribeiro, W. P. Barros, C. Ornelas and J. D. Megiatto Jr, Angew. Chem. 2018, 130, 9117-9121.

[14] E. Viola, M. P. Donzello, S. Ciattini, G. Portalone and C. Ercolani, Eur. J. Inorg. Chem. 2009, 2009, 1600-1607.

[15] C. Hu, B. C. Noll and W. R. Scheidt, Inorg. Chem. 2007, 46, 8258-8263.

[16] R. G. Pearson, Coord. Chem. Rev. 1990, 100, 403-425.

[17] a) T. Diao, P. White, I. Guzei and S. S. Stahl, Inorg. Chem. 2012, 51, 1189811909; b) M. Calligaris, Coord. Chem. Rev. 2004, 248, 351-375.

[18] F. A. Cotton, R. Francis and W. D. Horrocks, J. Phys. Chem. 1960, 64, 15341536.

[19] a) B. W. Musselman and N. Lehnert, Chem. Commun. 2020, 56, 14881-14884;

b) M. Goswami, P. Geuijen, J. N. H. Reek and B. de Bruin, Eur. J. Inorg. Chem. 2018, 2018, 617-626.

[20] a) F. Neese, Wiley Interdiscip. Rev. Comput. Mol. Sci. 2012, 2, 73-78; b) F. Neese, Wiley Interdiscip. Rev. Comput. Mol. Sci. 2018, 8, e1327. 
[21] a) B. O. Roos, V. Veryazov, J. Conradie, P. R. Taylor and A. Ghosh, J. Phys. Chem. B 2008, 112, 14099-14102; b) K. Pierloot, Q. M. Phung and A. Ghosh, Inorg. Chem. 2020, 59, 11493-11502; c) K. Pierloot, H. Zhao and S. Vancoillie, Inorg. Chem. 2010, 49, 10316-10329; d) J. Krzystek, A. Schnegg, A. Aliabadi, K. Holldack, S. A. Stoian, A. Ozarowski, S. D. Hicks, M. M. Abu-Omar, K. E. Thomas, A. Ghosh, K. P. Caulfield, Z. J. Tonzetich and J. Telser, Inorg. Chem. 2020, 59, 1075-1090. [22] S. Vancoillie, H. Zhao, V. T. Tran, M. F. A. Hendrickx and K. Pierloot, J. Chem. Theory Comput 2011, 7, 3961-3977.

[23] S. Stoll and A. Schweiger, J. Magn. Reson., Ser A 2006, 178, 42-55.

[24] a) SAINT+, Data Integration Engine, version 8.27b, Bruker AXS Inc., Madison, WI 2012; b) G. M. Sheldrick, SADABS: Program for Empirical Absorption Correction, version 2008/1; University of Göttingen: Göttingen, Germany. 2008; c) APEX2., Bruker AXS Inc, Madison, WI 2012; d) G. M. Sheldrick, SHELXL Version 2014/7; Program for Chrystal Structure Solution and Refinement, University of Göttingen, Germany 2014.

[25] G. M. Sheldrick, Acta Crystallogr. Sect. A: Found. Crystallogr. 2015, 71, 3-8. [26] G. M. Sheldrick, Acta Crystallogr. Sect. C: Cryst. Struct. Commun. 2015, 71, 3-8. [27] C. B. Hübschle, G. M. Sheldrick and B. Dittrich, J. Appl. Crystallogr. 2011, 44, 1281-1284.

[28] C. Adamo and V. Barone, J. Chem. Phys. 1999, 110, 6158-6170.

[29] F. Weigend and R. Ahlrichs, Phys. Chem. Chem. Phys. 2005, 7, 3297-3305. [30] V. Barone and M. Cossi, J. Phys. Chem. A 1998, 102, 1995-2001.

[31] a) S. Grimme, J. Comput. Chem. 2006, 27, 1787-1799; b) S. Grimme, J. Comput. Chem. 2004, 25, 1463-1473; c) S. Grimme, J. Antony, S. Ehrlich and H. Krieg, J. Chem. Phys. 2010, 132, 154104; d) S. Grimme, S. Ehrlich and L. Goerigk, J. Comput. Chem. 2011, 32, 1456-1465.

[32] a) R. Izsák and F. Neese, J. Chem. Phys. 2011, 135, 144105; b) J. Whitten, J. Chem. Phys. 1973, 58, 4496-4501; c) O. Vahtras, J. Almlöf and M. Feyereisen, Chem. Phys. Lett. 1993, 213, 514-518; d) F. Neese, F. Wennmohs, A. Hansen and U. Becker, Chem. Phys. 2009, 356, 98-109.

[33] a) K. Eichkorn, O. Treutler, H. Öhm, M. Häser and R. Ahlrichs, Chem. Phys. Lett. 1995, 240, 283-290; b) F. Weigend, Phys. Chem. Chem. Phys. 2006, 8, 1057-1065; c) K. Eichkorn, F. Weigend, O. Treutler and R. Ahlrichs, Theor. Chem. Acc. 1997, 97, 119-124. 
